\title{
Does competition foster trust? The role of tournament incentives
}

\author{
Steffen Keck • Natalia Karelaia
}

Received: 9 April 2010 / Accepted: 22 July 2011 / Published online: 26 August 2011

(C) Economic Science Association 2011

\begin{abstract}
Members of organizations are often called upon to trust others and to reciprocate trust while at the same time competing for bonuses or promotions. We suggest that competition affects trust not only within dyads including direct competitors, but also between individuals who do not compete against each other. We test this idea in a trust game where trustors and trustees are rewarded based either on their absolute performance or on how well they do relative to players from other dyads. In Experiment 1, we show that competition among trustors significantly increases trust. Competition among trustees decreases trustworthiness, but trustors do not anticipate this effect. In Experiment 2, we additionally show that the increase in trust under competition is caused by a combination of increased risk taking and lower sensitivity to non-financial concerns specific to trust interactions. Our results suggest that tournament incentives might have a "blinding effect" on considerations such as betrayal and inequality aversion.
\end{abstract}

Keywords Trust $\cdot$ Competition $\cdot$ Tournament incentives $\cdot$ Reciprocity $\cdot$ Betrayal aversion

JEL Classification C72 · C91

Electronic supplementary material The online version of this article (doi:10.1007/s10683-011-9297-1) contains supplementary material, which is available to authorized users.

S. Keck $(\varangle) \cdot$ N. Karelaia

INSEAD, Boulevard de Constance, 77305 Fontainebleau Cedex, France

e-mail: Steffen.Keck@insead.edu

N. Karelaia

e-mail: Natalia.Karelaia@insead.edu 


\section{Introduction}

Trust is an important determinant of economic performance both on national (Fukuyama 1995) and organizational levels (Bachmann and Zaheer 2006; Gambetta 1988; Kramer and Tyler 1996). In their daily work, members of organizations need to trust others and to reciprocate trust shown to them. On the other side, co-workers also frequently compete with each other for promotions and bonuses. For example, so called "up or out" rules are highly prevalent within professional service firms. Stirring intense competition among co-workers, these rules stipulate that best performing employees are promoted while their worse performing peers are required to leave the company (Kumra and Vinnicombe 2008). Moreover, many of the Fortune 500 companies such as General Electric, Cisco, Intel, and Hewlett Packard, among others, link parts of managers' individual benefits to relative performance (Boyle 2001). Similarly, parts of CEOs' compensations are often explicitly tied to how well they perform relative to their peers (Murphy 1998).

What are the effects of competition on trust and trustworthiness among individuals? Previous studies have shown that competitive reward structures which induce direct competition between partners in a work relationship decrease the level of trust between them (e.g., Ferrin and Dirks 2003; Tjosvold 1982, 1985). In contrast to existing literature, in this paper we suggest and experimentally test the idea that competition induced by tournament incentives not only affects trust between direct competitors, but also modifies the relationship between individuals who do not compete against each other. For example, a manager remunerated in comparison to the performance of managers in other divisions will have different trust relationships with her subordinates than a manager whose remuneration does not depend on how her performance compares to others. Similarly, relationships of business consultants and corporate lawyers with their clients will be influenced by intense competition for promotions and bonuses in their respective companies.

Although in the previous examples no competition exists between contestants and third parties, trust between them might still be crucial for their performance. A manager who can rely on and is in turn trusted by her subordinates is likely to perform better than if such trust is absent. The same is true for consultants or corporate lawyers who maintain reciprocal trust relationships with their clients. Supporting evidence for this idea comes from Dirks and Ferrin (2001) who, in a meta-analysis of previous empirical results, suggested that an individual's trust relationships within and outside the organization can have a considerable impact on her job performance. Following this line of reasoning, in this paper we focus on trust relationships between two individuals who do not compete against each other, but yet might contribute to each other's success by showing trust and acting reciprocally when trusted.

Prior research on competitive reward structures has not paid attention to the indirect effects of competition on such third party relationships. In practice, however, members of organizations are likely to interact just as much with third parties like clients, subordinates or co-workers from other divisions of the company as with their peers against whom they are ranked. It is intuitive that direct competition between individuals has a negative effect on trust and trustworthiness. By contrast, the effect of competitive incentives on trust relationships with third parties is less obvious. We 
argue that this indirect effect of competition within organizations is likely to be unacknowledged precisely because of its subtlety. Thus, the unintended effects of competitive reward structures in organizations would be underestimated if only direct effects were taken into consideration.

\subsection{Direct effect of competition}

Starting with the seminal research of Lazear and Rosen (1981), it has been suggested that competition induced by tournament-style reward schemes can be used to solve principal-agent problems and to achieve efficient outcomes. The idea behind the use of tournaments is that uncertainty about the performance of others and concerns about obtaining a bonus or being promoted causes individuals to work hard even without external supervision. Tournament theory also provides a rationale for hotly debated high pays of top managers. High compensations of a relatively small number of top managers function as a strong incentive for lower levels managers to exert high effort in order to be promoted (Rosen 1986).

To date, the evidence on the effect of competitive reward schemes on cooperation between individuals has been mainly negative. Lazear (1989) provided a model where a worker can exert two kinds of effort: effort that increases the worker's own output and effort that "sabotages" (i.e., reduces) other workers' outputs. His results showed that tournaments in such settings induce both productive and sabotage efforts. Experimental evidence for non-cooperative behavior and sabotage in tournaments shows that given the option, individuals exert considerable effort to sabotage direct competitors, thereby hurting overall efficiency (Harbring and Irlenbusch 2008). Irlenbusch and Ruchala (2008) showed that although tournament type incentives in the form of a bonus payment for the highest contributor in a team can increase individual efforts, they might also crowd out voluntary cooperation in the team.

Studies that focused specifically on the effect of competitive rewards on trust demonstrated that individuals trust less in their work partners under a competitive reward scheme than under a non-competitive scheme (Ferrin and Dirks 2003; Tjosvold 1982, 1985). Lower trust under competitive rewards is partially due to changes in trustors' beliefs about their partners' motives and future behavior (Ferrin and Dirks 2003). Moreover, competitive reward structures might have enduring effects in organizations even after they have been abolished. Previous experimental evidence suggests that exposure to tournament incentives in a preceding unrelated task reduces expectations of trust in subsequent dyadic relationships (Harbring 2010).

All these previous studies focused on the effects of direct competition between team members on trust relationships. By contrast, we explore the effects of competitive incentives on trust and reciprocity in relationships with third parties. As our results show, the role of competition in this case is more complex than what has been found in studies that focused on direct competition.

\subsection{Indirect effect of competition on trust and trustworthiness}

In this paper, we compare trust and reciprocity in situations where individuals are rewarded based on their absolute performance and where rewards are based on their 
standing relative to other individuals not involved in the trust relationship. For this purpose, we combine a standard trust game adapted from Berg et al. (1995) with a winner-take-all tournament. In the trust game, participants play in pairs. In each pair, the trustor decides whether to trust her counterpart, and the trustee decides whether to reciprocate trust. In our two experiments, either two or three dyads were formed in each session, such that at any moment there were either two or three participants playing the game in the same role. We operationalized competition by modifying payoff structures in different experimental conditions. The payoffs of participants were either based on their absolute performance as in the standard trust game or determined by their standing relative to other participants who played the game in the same role.

By introducing competition with other players in the trust game, tournament incentives add additional strategic considerations for decision makers. In particular, tournament incentives might change decision makers' general willingness to take on risk as they try to maximize their chances of obtaining the tournament prize. For example, Gaba and Kalra (1999) showed that highly competitive tournament environments increase risk taking. They provided a theoretical solution showing that when the proportion of winners in a tournament is small (with a winner-take-all tournament as the most extreme case), it is optimal for individuals to take high risks, while the opposite holds for tournaments with a large proportion of winners. These predictions were further tested experimentally in a series of contests in which participants took the role of a member of a sales force and had to maximize their sales by selecting between segment types with different variance levels. The results supported the theoretical predictions in that participants made riskier decisions when the proportion of winners in the contest was smaller. Likewise, Hvide (2002) demonstrated theoretically that an incentive scheme rewarding the best performing individual in the group can cause agents to choose low levels of effort combined with high levels of risk.

The literature on risk taking in tournaments may imply that in competitive environments, people would also be willing to accept higher risks when they come from another person, i.e., would be willing to trust more. However, two considerations put this direct extrapolation in doubt. First, some studies reported no significant relationship between individual risk attitudes and the propensity to trust strangers (Eckel and Wilson 2004; Houser et al. 2010). Second, taking a risky bet is not equivalent to the decision to trust a stranger as the latter often requires an additional premium to compensate for the cost of "trust betrayal" or disadvantageous inequality (Aimone and Houser 2010; Bohnet and Zeckhauser 2004; Hong and Bohnet 2007). We address this issue directly in Experiment 2 the goal of which was to disentangle the effect of tournament incentives on pure risk taking and their effect on trust relationships.

A further question that we address in this paper is whether trustees competing for rewards with others honor trust in their relationships with third parties uninvolved in competition. Trustworthiness is often attributed to unconditional kindness, inequality aversion, and reciprocal preferences (Ashraf et al. 2006). When facing competitive pressures, are individuals still sensitive to the distribution of outcomes they generate? Do they still reciprocate trust shown to them? On one side, the desire to avoid inequality and return back the favors of others might be strong enough to persist even under competitive pressures. Indeed, people are often motivated to maintain positive views 
of themselves, both privately and publicly (Aquino and Reed 2002; Greenwald 1980; Monin and Jordan 2009). On the other side, competitive pressures may reduce the sensitivity to considerations different from outperforming the others, "winning," and getting the financial prize (Malhotra 2010). For example, competition has been shown to increase cheating among poor performers (Schwieren and Weichselbaumer 2010) and overall shift the focus from long-term to short-term goals (Brown et al. 1996). We place trustees under competitive pressures and study their behavior towards third parties in Experiment 1.

The results of Experiment 1 show that competition among trustors significantly increases trust. We also find that competition among trustees decreases their willingness to reciprocate trust. However, trustors do not anticipate this effect. This, in turn, leads to a negative mean payoff to trust when only trustees are paid based on relative performance. In Experiment 2, we compare the effect of tournament incentives on trust in third parties with the trustors' behavior in an analogous risk game that does not involve a human trustee. We show that the impact of tournament incentives on trust extends over and beyond what would be expected from the effect of tournaments incentives on risk taking. Overall, our results suggest that tournament incentives might have a "blinding effect" on non-financial considerations such as, for example, betrayal and inequality aversion.

\section{Experiment 1}

\subsection{Design}

The experiment was designed to investigate the effect of competition on trust relationships among individuals who do not compete with each other. We run modified versions of a standard two-person, anonymous one-shot trust game devised by Berg et al. (1995) that has been traditionally used to measure trust and trustworthiness (e.g., Glaeser et al. 2000). Three dyads were formed in each session, such that an an moment there were three participants playing the game in the same role. We operationalize competition by manipulating payoff structures. Payoffs were either standard (i.e., absolute evaluation of outcomes) or tournament-based (i.e., evaluation of outcomes relative to others).

The experiment had a 2 (incentives for trustors: standard or tournament) $\times 2$ (incentives for trustees: standard or tournament) between-subject design. Table 1 gives an overview of the four conditions. The baseline condition is a standard trust game

Table 1 Experimental conditions

\begin{tabular}{llll}
\hline Condition & Incentives for trustors & Incentives for trustees & No. of dyads \\
\hline Baseline & Standard & Standard & 33 \\
Trustor-tournament & Tournament & Standard & 30 \\
Trustee-tournament & Standard & Tournament & 30 \\
Trustor- and trustee-tournaments & Tournament & Tournament & 30
\end{tabular}


where both trustor and trustee are paid according to their absolute performance. In the trustor-tournament and trustee-tournament conditions, one of the two players in the dyad is paid according to their ranking relative to peers playing the same role in other dyads. By changing the payoff structure in this manner we are able to isolate the separate effects of competition on trust and trustworthiness. Finally, in the trustorand trustee-tournaments condition trustors and trustees are evaluated relative to their peers from the other dyads.

Both players received an endowment of 40 experimental points at the beginning of the game. Trust is measured by the number of points $X \leq 40$ that the trustor decides to invest. Any amount invested was tripled by the experimenter, such that the trustee received $3 \times X$. The trustee could return any amount $Y \leq 3 \times X$ to her trustor. The proportion of points sent back $R=Y /(3 \times X)$ is a measure of trustworthiness. The final number of points is $(40-X+Y)$ for the trustor and $(40+3 \times X-Y)$ for the trustee. As trustees have no economic incentives to send any points back, the unique equilibrium of the game is $X=Y=0$.

In the baseline condition, the points were exchanged at the rate of 10 points $=1 €$. In the trustor- (trustee-) tournament condition, trustees (trustors) exchanged their points at the same rate, while the three trustors (trustees) were ranked based on their final number of points. The payoff for the trustor (trustee) with the highest number of points - the winner of the tournament—was fixed at $12 €$, while the other two trustors (trustees) received nothing. All ties were resolved at random. Finally, in the trustor- and trustee-tournament condition, the best performers within the groups of trustors and trustees received $12 €$, while the other players received nothing. ${ }^{1}$ Information about the payoff schemes of trustors and trustees was common knowledge in all conditions.

\subsection{Procedure and participants}

The experiment was conducted at the INSEAD Social Science Research Centre in Paris, France. All instructions were given in French. An English translation of the instructions is provided in the online supplementary material. Participants were recruited through invitations outside the Sorbonne University in Paris and paid a showup fee of $5 €$ in addition to their earnings in the trust game. In total 246 participants (147 women and 99 men) took part in the experiment. We ran multiple sessions involving six participants, i.e., three dyads. We conducted 11 sessions (with 66 participants in total) for the baseline condition and 10 sessions (with 60 participants in total) for each of the other three conditions. No participant took part in more than one session. Participants were between 18 and 45 years of age, mean age was 22. Total earnings per participant (excluding the show-up fee of $5 €$ ) were between $0 €$ and $15.7 €$ with a mean of $5.0 €$.

Upon arrival to the laboratory, participants were distributed between six individual rooms. The experiment was fully computerized and programmed in ASP.NET. The

\footnotetext{
${ }^{1}$ If players follow the game-theoretic prediction of $X=Y=0$, the final expected payoff under both standard and tournament schemes is $4 €$. Under the standard scheme, players' endowments of 40 points are exchanged to $4 €$. Under the tournament scheme, if $X=Y=0$ for all dyads, each player has a $1 / 3$ chance of winning $12 €$, which is equivalent to an expected payoff of $4 €$.
} 
instructions were provided in duplicate on the computer screens and on paper-so that participants could consult them at any moment of the experiment. Prior to the game, participants answered nine quiz questions designed to test their understanding of the experimental procedures. All doubts were resolved by the experimenter during this process. Participants were then randomly assigned to the role of trustor (called in the instructions "A-player") or trustee (called in the instructions "B-player"). Importantly, to make sure that participants paid attention to the incentive schemes for both trustors and trustees, we assigned them to their roles only after they had finished reading the instructions and answered all quiz questions correctly.

After deciding how many points to send to trustees, trustors indicated: (1) what they expected to receive back; and (2) their expectation of what the other two trustors sent, on average, to their trustees. After deciding how many points to return back to trustors, trustees indicated: (1) how fair and selfish the decision made by their trustors was (on scales from 1 to 4); (2) their expectations of how many points the other two trustees received, on average; and (3) their expectations of how many points the other two trustees sent back, on average. ${ }^{2}$ Trustors then received feedback on how many points their trustees sent them back and asked to indicate how fair and selfish the decision made by their trustees was (on scales from 1 to 4). Feedback on the number of points gained by two other participants who played the game in the same role was then provided, followed by information on individual earnings and the debriefing. ${ }^{3}$

\subsection{Results}

\subsubsection{Overview}

We measure trust as the number of points sent by trustors $(X)$. Accordingly, our measure of trustworthiness $(R)$ is the ratio between the number of points trustees sent back $(Y)$ and the points they received $(3 \times X)$, that is, $R=Y /(3 \times X) \cdot{ }^{4}$ After trustors made their decisions, we asked them how many points they expected to receive back $(E[Y])$. Based on this forecast we calculate expected trustworthiness $(E[R])$ as the expected return divided by the tripled amount of points trustors sent, that is: $E[R]=$ $E[Y] / 3 \times X{ }^{5}$ Table 2 summarizes experimental results.

On average, trustors sent 21 points of their 40-point endowment to trustees. Out of 123 trustors, $21 \%(n=26)$ sent all their endowments to trustees, $6 \%(n=7)$ sent nothing. Trustees who received a non-zero amount $(n=116)$ returned on average $38 \%$ of the points they received. On average, trust paid off financially as trustors obtained a return on trust of $15 \%$. The mean amounts sent and returned are close to

\footnotetext{
${ }^{2}$ In order to limit the complexity of the instructions and allow participants to focus on their decisions in the game we chose not to reward participants for the accuracy of their expectations.

${ }^{3}$ At the end of the experiment, after the trust game, participants had a possibility to donate some or all of their earnings to a charity. There was no correlation between donations and incentive schemes.

${ }^{4}$ We excluded seven trustees who received 0 points $(X=0)$ from the analysis of trustworthiness.

${ }^{5}$ For trustors who sent zero points and consequently expected a zero return $(X=0$ and $E[Y]=0)$, we set $E[R]=1 / 3$. We exclude one trustor who expected to receive back more than three times the number of points she sent.
} 


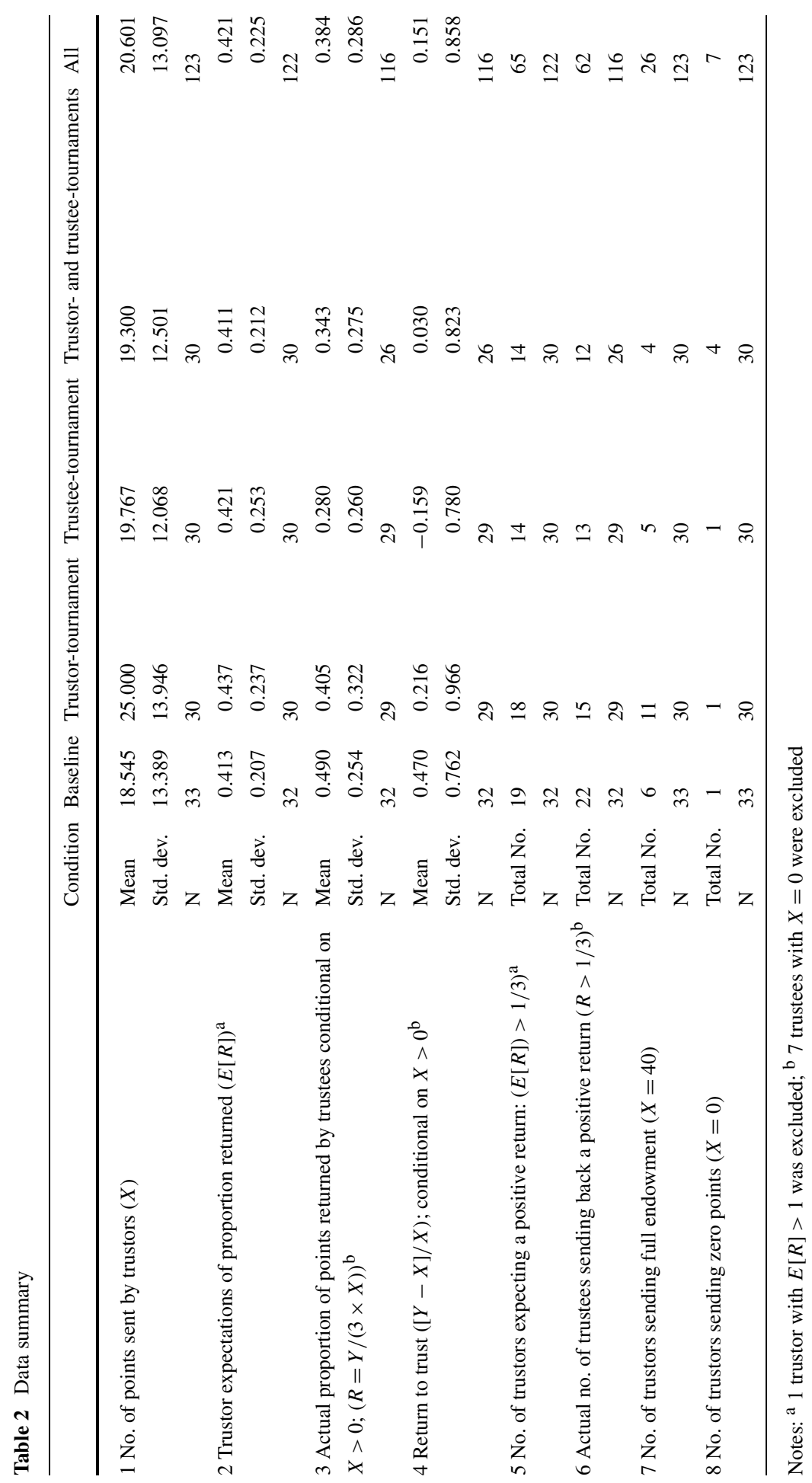


the standard results in trust games where trustors send about $50 \%$ of their endowment and trustees, on average, return about one third of the tripled amount (Camerer 2003).

Across all four conditions, trustors expected trustees to send back on average $42 \%$ of the points they received. Of all trustors, 53\% $(n=65)$ expected back more than they had sent, and $47 \%(n=57)$ expected a zero or negative return to trust. On average, the first group sent 23 points to their trustees, while the second group sent 17 points (Mann-Whitney U-test [henceforth MW]: $z=-2.83, p<0.01$ ). ${ }^{6}$ The proportion of trustors expecting a positive return on trust, 53\%, is relatively high as compared to what was found in similar experiments. For example, Ashraf et al. (2006) reported that only $36 \%$ of their trustors expected back more than they had sent.

\subsubsection{Trustors' decisions}

In the trustor-tournament condition, trustors sent on average 25 points (Table 2), which is more than the average of 19 points sent across other conditions (MW for the trustor-tournament condition and the baseline condition: $z=-1.88, p=0.06$ ). On the other side, the level of trust was similar in the trustee-tournament and the baseline condition (MW: $z=-0.74, p=0.46$ ), as was expected trustworthiness (MW: $z=0.79, p=0.43)$. Finally, neither trust nor expected trustworthiness differed between the trustor- and trustee-tournaments condition and the baseline condition (MW: $z=-0.55, p=0.58$ for trust, and $z=0.42, p=0.67$ for expected trustworthiness).

Although a somewhat smaller number of trustors expected a positive return to trust in the conditions where trustees were involved in tournaments $(n=14$ in both, Table 2) compared to other conditions ( $n=19$ and 18 for the baseline and the trustortournament condition, respectively), the difference is not statistically significant (twosample proportion test: $z=1.44, p=0.14$ ).

To further analyze the behavior of trustors, we employ a regression analysis of the number of points sent by trustors. We include several explanatory variables. First, three dummy variables capture the effect of competitive rewards either on the side of trustors or trustees, or both (trustor-tournament, trustee-tournament, and trustor- and trustee-tournaments). Second, we are interested in assessing the effect of expected trustworthiness on trust. It is reasonable to assume that trustors who expect a positive return to trust send more points than those who do not. To capture this effect, we code a dummy variable "positive expected return" ( 1 if $E[R]>1 / 3$ and 0 otherwise). Third, to identify potential variations of the effect of expected trustworthiness across conditions, we add an interaction term for each condition. Fourth, prior research has demonstrated gender differences in both absolute levels of trust as well as underlying trust motives (for an overview, see Innocenti and Pazienza 2006). We therefore include gender (female $=1$ ) as well as an interaction term between gender and expected positive return to the regression. Finally, we add a dummy variable for economics major students. Table 3 shows the results from a standard OLS regression.

The coefficient of the trustor-tournament condition is positive and significant, implying that trustors sent more points in this condition than in the baseline condition. The effects of other conditions are not significant, in line with the non-parametric

${ }^{6}$ All $p$-values are based on two-tailed tests. 
Table 3 Determinants of trustors' decisions

\begin{tabular}{|c|c|}
\hline Dependent Variable & Points sent $(X)$ \\
\hline Constant & $\begin{array}{l}11.624^{* * *} \\
(4.447)\end{array}$ \\
\hline Trustor-tournament & $\begin{array}{l}13.24^{* * *} \\
(5.017)\end{array}$ \\
\hline Trustee-tournament & $\begin{array}{c}2.063 \\
(4.792)\end{array}$ \\
\hline Trustor- and trustee-tournaments & $\begin{array}{r}-0.181 \\
(4.76)\end{array}$ \\
\hline Gender $(0=$ male; $1=$ female $)$ & $\begin{array}{c}4.250 \\
(3.601)\end{array}$ \\
\hline Positive Expected Return ( 1 if $E[R]>1 / 3,0$ otherwise) & $\begin{array}{c}13.646^{* *} \\
(5.518)\end{array}$ \\
\hline Positive Expected Return $\times$ Trustor-tournament & $\begin{array}{r}-12.508^{*} \\
(6.507)\end{array}$ \\
\hline Positive Expected Return $\times$ Trustee-tournament & $\begin{array}{r}-1.196 \\
(6.490)\end{array}$ \\
\hline Positive Expected Return $\times$ Trustor- and trustee-tournaments & $\begin{array}{c}3.014 \\
(6.485)\end{array}$ \\
\hline Positive Expected Return $\times$ Gender & $\begin{array}{r}-8.283^{*} \\
(4.816)\end{array}$ \\
\hline Economics Major & $\begin{array}{r}-2.591 \\
(3.355)\end{array}$ \\
\hline Observations $^{\mathrm{a}}$ & 122 \\
\hline Adjusted $R^{2}$ & 0.082 \\
\hline
\end{tabular}

Notes: Results from OLS-regression; Standard errors in parentheses

${ }^{*}$ Significant at $10 \% ;{ }^{* *}$ Significant at $5 \% ;{ }^{* * *}$ Significant at $1 \% ;{ }^{\text {a }} 1$ trustor with $E[R]>1$ was excluded

analysis. As expected, the coefficient of the dummy variable indicating positive expected returns to trust is positive and significant. Furthermore, we find a significant negative interaction effect of positive expected returns and the trustor-tournament condition. The net effect of positive expected returns in the trustor-tournament condition is close to zero. This suggests that the increase in trust under tournament incentives was not driven by higher expectations concerning trustees' trustworthiness but by competitive pressure.

The effect of gender is not significant. However, we find a marginally significant negative interaction effect of gender and expected returns. This implies that compared to men, women's decision to trust were based less on expected positive return but more on other motives, for example, altruistic preferences or social norms. Similarly to this result, Innocenti and Pazienza (2006) reported that women behave more altruistically in the trust game both in the role of trustors and trustees. 
As reported above, when only trustors participate in competition, they sent more points to their trustees. However, trust was not higher in the condition where both trustors and trustees participated in tournaments. In fact, while competitive pressure in the trustor-tournament condition increased the number of trustors exhibiting full trust, it increased the number of those who did not trust at all in the trustor- and trustee-tournaments condition. As Table 2 shows, high trust in the trustor-tournament condition was to a large extent driven by a relatively large number of trustors who sent their whole endowment to trustees ( $n=11$ vs. $n=5$ in the baseline condition). Instead, in the trustor- and trustee-tournaments condition more people chose not to send anything to their trustees ( $n=4$ vs. $n=1$ in the baseline condition).

Interestingly, trustors were not sensitive to the competitive rewards for trustees in the trustee-tournament condition. It is possible that in the most competitive trustorand trustee-tournaments condition where all players participated in tournaments, the similarity of incentive schemes for trustors and trustees enabled trustors to anticipate better the lower reciprocity of trustees. As a consequence, they trusted less than they did when facing only own competitive incentives (i.e., the trustor-tournament condition).

\subsubsection{Trustees' decisions}

Trustworthiness was lower when trustees competed for rewards (MW: $z=3.01, p<$ 0.01 for the trustee-tournament condition vs. the baseline condition, and $z=2.26$, $p=0.02$ for the trustor- and trustee-tournaments condition vs. the baseline condition). Moreover, the trustworthiness level was the same in the two conditions where trustees participated in tournaments (trustee-tournament condition and trustor- and trustee-tournaments condition, MW: $z=0.90, p=0.37$ ). On the other side, trustworthiness did not differ between the trustor-tournament condition and the baseline condition (MW: $z=1.36, p=0.17$ ).

One consequence of the lower trustworthiness under tournament incentives for trustees was that returns to trust turned negative in the trustee-tournament condition and, on average, were not different from zero in the trustor- and trustee-tournaments condition, as Table 2 shows (mean return across both conditions $=-0.07 ; t=-0.64$, $p=0.52$ ). By contrast, returns to trust were significantly greater than zero under standard incentives for trustees (mean return to trust across the baseline and the trustortournament conditions $=0.35, t=3.15, p<0.01$ ).

Some previous studies have reported that trustees who receive larger amounts from their trustors send back a higher proportion of their money (e.g., Ashraf et al. 2006; Bellemare and Kröger 2007; Chaudhuri and Gangadharan 2007; Schotter and Sopher 2006), while others did not find a link between the amounts sent and the proportions returned (Berg et al. 1995; Csukas et al. 2008; Willinger et al. 2003). We thus next analyze whether trust causes trustworthiness in our data. Table 4 shows the results from an OLS regression with trustworthiness $(R=Y /(3 \times X))$ as the dependent variable. The predictors include the number of points received $(3 \times X)$, dummy variables for experimental conditions, and demographic factors. ${ }^{7}$ In addition, we include the

\footnotetext{
${ }^{7} \mathrm{We}$ also tested for interactions between gender and conditions. None of the interaction terms was significant.
} 
Table 4 Determinants of trustees' decisions

\begin{tabular}{lc}
\hline Dependent Variable & Trustworthiness \\
& $(R=Y /(3 \times X))$ \\
\hline Constant & $0.558^{* * *}$ \\
Trustor-tournament & $(0.083)$ \\
Trustee-tournament & -0.084 \\
& $(0.073)$ \\
Trustor- and trustee-tournaments & $-0.227^{* * *}$ \\
Gender $(0=$ male; $1=$ female $)$ & $(0.073)$ \\
& $-0.148^{* *}$ \\
Points Received $(3 \times X)$ & $(0.075)$ \\
& -0.011 \\
Subjective Trust Level & $(0.055)$ \\
$(1$ if $X-$ ExpXothers $<0,0$ otherwise $)$ & -0.001 \\
Economics Major & $(0.002)$ \\
Observations ${ }^{\mathrm{a}}$ & $-0.126^{* *}$ \\
\hline
\end{tabular}

Notes: Results from OLS-regression; Standard errors in parentheses

${ }^{*}$ Signifîcant at $10 \% ;{ }^{* *}$ Significant at $5 \% ;{ }^{* * *}$ Significant at $1 \% ;{ }^{\text {a }} 7$ trustees for whom $X=0$ were excluded

subjective evaluation of trust by trustees as another predictor. As described above, after trustees made their decisions, they indicated how many points on average they expected the other two trustees to have received $(3 \times$ ExpXothers $)$. The difference between the estimate for others and the number of points they received themselves $(3 \times X)$ provides a measure of their subjective perception about the level of trust shown to them. A trustee who thinks that others received more points than she did will probably be less willing to reciprocate. We thus coded a dummy variable "subjective trust level" (STL) as 1 if ( $X-$ ExpXothers) $<0$ and as 0 otherwise.

Table 4 shows that the negative effect of tournament incentives on trustworthiness stays significant when controlling for other factors (coefficients of the trusteetournament condition and the trustor- and trustee-tournaments condition). The number of points received does not have a significant effect on reciprocity. However, the subjective measure of trust level (STL) has a significant negative effect. This suggests that whether people appreciate and honor trust is mainly determined by their own subjective perceptions and expectations concerning the amount of trust rather than its objective level. 


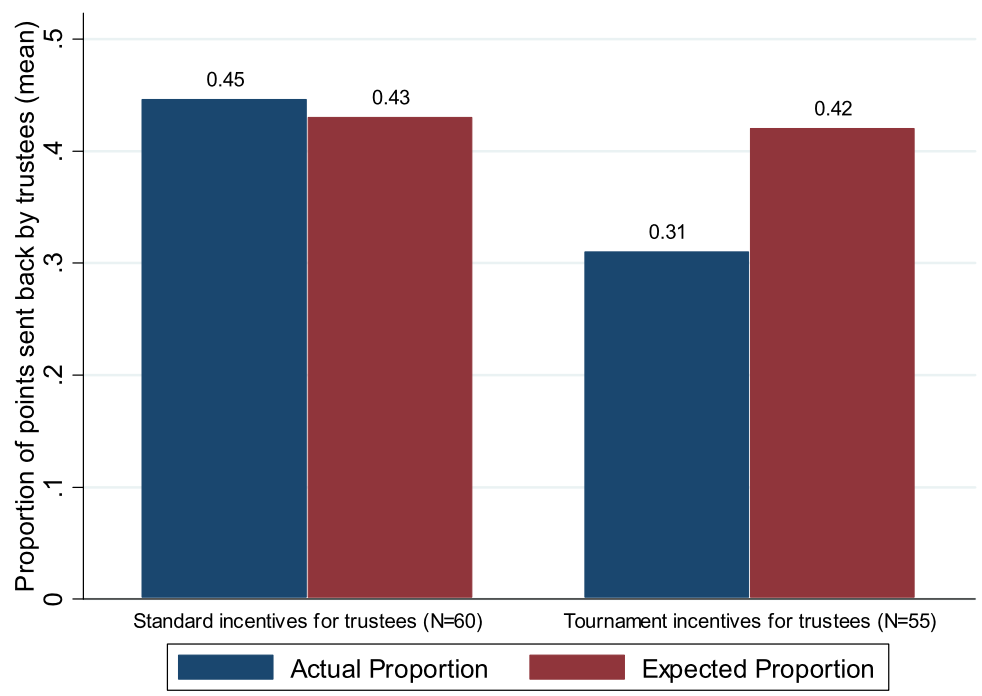

Fig. 1 Expected and actual trustworthiness under standard and tournament trustee-incentives

\subsubsection{Accuracy of trustors' expectations}

In this section we analyze how accurate trustors were in forecasting trustworthiness. To do so, we explore whether trustors' expectations were biased towards overor under-prediction. In a cross-cultural experiment, Bohnet and Zeckhauser (2004) found that in all countries studied trustors in the standard trust game-corresponding to our baseline condition-made unbiased forecasts, possibly due to the knowledge about local social norms.

As discussed above, trust remained constant across the baseline, trustee-tournament, and trustor- and trustee-tournaments conditions, as did expected trustworthiness. On the other side, actual trustworthiness was significantly lower under competitive incentives for trustees, as compared to standard incentives. Thus, the accuracy of trustors' forecasts varied with the incentives for trustees. Figure 1 shows the mean proportion of points that trustors expected to receive back and the mean actual proportion, separately for competitive and non-competitive incentives for trustees.

Similar to the findings of Bohnet and Zeckhauser (2004), the results in Fig. 1 show that when trustees are paid according to standard incentives, trustors' expectations were close to the actual proportion returned (Wilcoxon signed-rank test [henceforth WS]: $z=-0.61, p=0.53$ ). However, when trustees were paid according to tournament incentives, trustors systematically overestimated returns (WS: $z=2.17$, $p=0.03){ }^{8}$ While being unbiased in the case of standard incentives for trustees,

\footnotetext{
${ }^{8}$ We excluded from the analysis those trustors who sent no points $(X=0)$. Including them and setting $E[R]=1 / 3$ and $R=1 / 3$ does not change the conclusions. We also excluded one trustor who expected to receive back more than three times as many points as she sent. Including this participant does not change the results either.
} 
Table 5 Determinants of perceived fairness of trustees' decisions

\begin{tabular}{lcc}
\hline Dependent Variable: Perceived Trustee Fairness & Model 1 & Model 2 \\
\hline Trustee tournaments $(1$ for the two conditions & $-0.566^{*}$ & -0.58 \\
with tournament incentives for trustees, & $(0.341)$ & $(0.547)$ \\
0 for the other two conditions) & & 0.281 \\
Gender $(0=$ male; $1=$ female) & $(0.616)$ \\
Economics Major & & -0.038 \\
& & $0.528)$ \\
Positive Expected Return $(1$ if $E[R]>1 / 3$, & -0.888 \\
0 otherwise) & & $(0.739)$ \\
Positive Expected Return $\times$ Gender & & 0.298 \\
& & $(0.793)$ \\
Positive Expected Return $\times$ Trustee-tournaments & 0.718 \\
Proportion received back $(R=Y /(3 \times X))$ & $(0.73)$ \\
& & $3.698^{* * *}$ \\
Observations & & $(0.730)$ \\
Pseudo $R^{2}$ & 115 & 115 \\
\hline
\end{tabular}

Notes: Results from ordered-logit regression; Standard errors in parentheses

${ }^{*}$ Significant at $10 \% ;{ }^{* *}$ Significant at $5 \% ;{ }^{* * *}$ Significant at $1 \% ;{ }^{a} 1$ truster with $E[R]>1$ and 7 trustors with $X=0$ were excluded

trustors failed to anticipate the differences in trustworthiness arising from competition among trustees and thus over-predicted returns.

\subsubsection{Perceived fairness}

After the completion of the game and before final outcomes were announced, both trustors and trustees rated how fair they thought the decisions made by their partners were, on a scale from 1 (very unfair) to 4 (very fair). ${ }^{9}$ Tables 5 and 6 show the results from ordered-logit regressions with the perceived fairness of trustors and the perceived fairness of trustees as dependent variables.

As Model 1 in Table 5 shows, trustors thought that the decisions made by their trustees were less fair when trustees competed for rewards. This effect is entirely due to lower trustworthiness levels under competition among trustees (Model 2). Trustworthiness is the only variable that determines perceived fairness. It appears that trustors did not take into account that trustees had additional motivations and constraints resulting from competitive incentives. As established above, trustors were insensitive to the incentives for trustees when forecasting the returns to trust. This insensitivity seems to persist in their evaluations of how fair trustees' decisions were.

\footnotetext{
${ }^{9}$ We also asked participants how selfish they thought the decisions of their partners were. We obtain similar results with this measure as with perceived fairness.
} 
Table 6 Determinants of perceived fairness of trustors' decisions

\begin{tabular}{lcc}
\hline Dependent Variable: Perceived Truster Fairness & Model 1 & Model 2 \\
\hline Trustor-tournament & 0.557 & 0.291 \\
& $(0.453)$ & $(0.488)$ \\
Trustee -tournament & -0.179 & -0.294 \\
& $(0.444)$ & $(0.473)$ \\
Trustor- and trustee-tournaments & 0.669 & 0.700 \\
& $(0.466)$ & $(0.499)$ \\
Gender $(0=$ male; $1=$ female) & & -0.388 \\
& & $(0.366)$ \\
Economics Major & & -0.355 \\
& & $(0.427)$ \\
Subjective Trust Level & & $-0.693^{*}$ \\
$(1$ if $X-$ ExpXothers $<0,0$ otherwise) & & $(0.413)$ \\
Points received $(3 \times X)$ & & $0.058^{* * *}$ \\
& & $(0.017)$ \\
Observations & 123 & 123 \\
Pseudo $R^{2}$ & 0.014 & 0.103 \\
\hline
\end{tabular}

Notes: Results from ordered-logit regression; Standard errors in parentheses

* Significant at $10 \% ;{ }^{* *}$ Significant at $5 \% ;{ }^{* * *}$ Significant at $1 \%$

As Table 6 shows, the results are similar for trustees. The only significant driver of whether they perceive the decisions made by their trustors as fair is the number of points they received. This shows that both trustors and trustees did not take into account the incentives of their partners when assessing fairness.

\subsection{Discussion}

The results of Experiment 1 show that tournament incentives have a significant effect on both trust and trustworthiness in the relationship with third parties not involved in competition. Trustors invested significantly more points when rewarded by tournament incentives compared to a payoff scheme based on absolute performance. On the other side, tournament incentives caused trustees to send back a lower proportion of points. Tournament incentives seem to reduce the concerns for equality and reciprocal preferences that have been suggested to explain trustworthiness (Ashraf et al. 2006). Our results also showed that trustors did not anticipate this decrease in trustworthiness. In particular, while their expectations were close to real returns when trustees were rewarded based on absolute performance, trustors significantly overestimated returns for the case of tournament incentives on the side of trustees.

One limitation of Experiment 1 with respect to the measurement of trust is that it does not allow to distinguish between the effects of tournament incentives on pure risk taking (e.g., caused by strategic considerations about winning the tournament price) and the effects specific to trust relationships such as, for example, concerns about being betrayed or creating a disadvantageous inequality between trustors and 
trustees. We address this issue in Experiment 2 that was designed to explicitly distinguish between the two forces.

\section{Experiment 2}

\subsection{Design}

Experiment 2 had two main goals. First, we aimed to replicate our finding that tournament incentives increase trust in dyadic relationships. Second, we sought to explicitly distinguish between the effect of tournament incentives on pure risk taking and their effect on trust. For this purpose, we compare trust behavior in the standard trust game and its analogue in the so-called "risk game", adapted from Kosfeld et al. (2005). The risk game was identical in structure to the trust game with the only difference that trustors did not play against a human trustee but against a computer. The latter determined how many points $(Y)$ to sent back using a random distribution of returns. This return distribution in the risk game was parametrized using the actual return decisions made by trustees in the trust game. Thus, trustors in the risk game were facing the same expected monetary payoffs as in the trust game. ${ }^{10}$

In Experiment 1, we established the effect of tournament incentives on trust decisions in a between-subject design. Experiment 2 was a within-subject design in which trustors made a separate decision for each of the two incentive schemes (i.e., baseline and tournament). Such design allows us to analyze the effect of incentive schemes at individual level and thus gives us more control over individual variability (see Camerer 2003, for a discussion of within-subject designs). The order in which trustors made their two decisions was counterbalanced. Whereas the incentive schemes were manipulated within-subject, each participant took part in only one of the two games, either the trust- or the risk game. Thus, the experiment followed a 2 (risk game vs. trust game) $\times 2$ (standard vs. tournament incentives for trustors) mixed design where the first factor was between-subject, while the second factor was within-subject. We focused on the incentives for trustors only in this experiment and did not vary the incentives on the side of trustees. They were paid according to standard incentives in all conditions. Therefore, the trust game in Experiment 2 essentially replicates the baseline and the trustor-tournament condition from Experiment 1.

Trustees made two decisions in counterbalanced order-one for the case of standard incentives for trustors and one for the case of tournament incentives for trustors. In order to gather sufficient data to compute the return distributions for the risk game, we employed the strategy method for trustees. In particular, trustees made a decision about how many points to send back $(Y)$ for each possible decisions trustors could make, except an investment of 0 points. Only one of the two within-subject conditions (i.e., standard or tournament) was randomly selected at the end of the game to determine final payoffs.

\footnotetext{
${ }^{10}$ As trustors in the trust game do not know the real return distribution, we also asked them to indicate their expectations about returns. This allows us to test for differences between the real return distribution that we used for the risk game and trustors' expectations on which their decisions in the trust game were based.
} 
In Experiment 2, competition involved only two trustors (instead of three, as in Experiment 1). This makes the experiment more tractable and also allows us to test the robustness of our previous results in a setting with fewer competitors. Similar to Kosfeld et al. (2005), trustors also had a more limited choice with respect to how much of their endowment to invest $(X)$. Trustors were endowed with eight experimental points and could choose between investing $0,2,4,6$ or 8 points. In the trust game, points invested were doubled and sent to the trustee. Trustees were also endowed with eight points at the start of the game but could not send back more points then they received from trustors $(2 \times X)$. Under standard incentives, each point was worth $0.50 €$ to participants. Under tournament incentives, points gained by the two trustors were compared, and the trustor with more points received $8 €$, while the other trustor received nothing. ${ }^{11}$ Draws were resolved randomly. All information about incentive schemes was common knowledge.

\subsection{Participants and procedure}

We employed the same recruitment and experimental procedure as in Experiment 1. In total 88 participants (50 women and 38 men) took part in Experiment 2 ( 28 trustors in the risk game condition; 30 trustors and 30 trustees in the trust game condition). Participants were between 18 and 31 years of age, mean age was 23. Total earnings per participant (excluding the show-up fee of $4 €$ ) were between $0 €$ and $12 €$ with a mean of $4.5 €$. $^{12}$

In order to collect the data for the return distribution, we ran the trust game condition first. We then used the data collected to construct the return distribution for the risk game condition. Sessions always involved four participants who were assigned to isolated cubicles upon entry to the lab and did not have any face-to-face contact with each other neither during nor after the experiment. After having made their decisions, trustors were asked to indicate how many points they would have expected to receive back for each possible decision they could have made. This allows us to compare trustors' expectations with the actual returns for each of the five possible investments. ${ }^{13}$ At the end of the study, participants answered a brief questionnaire that asked for demographic information. Before being dismissed all participants were fully debriefed. An English translation of the instructions is provided in the online supplementary material.

\subsection{Results}

\subsubsection{Order effects}

The order of presentation did not have a significant effect on investment decisions under standard incentives (MW: $z=0.15, p=0.88$ for the trust game; MW: $z=$

\footnotetext{
${ }^{11}$ If players follow the game-theoretic prediction of $X=Y=0$, the final expected payoff under both standard and tournament schemes is $4 €$.

${ }^{12}$ Thirteen participants ( 6 in the trust game and 7 in the risk game) lost the tournament and received only their show-up fee. Participants did not express any concerns about the payment procedure in the debriefing. ${ }^{13}$ As in Experiment 1, we chose not to incentivize the elicitation of expectations in order to limit the complexity of the experiment for participants.
} 
Table 7 Expected and actual returns in the trust game

\begin{tabular}{|c|c|c|c|c|c|c|c|c|}
\hline \multirow[t]{3}{*}{ Investment } & \multicolumn{4}{|c|}{ Standard incentives $(N=30)$} & \multicolumn{4}{|c|}{ Tournament incentives $(N=30)$} \\
\hline & \multicolumn{2}{|c|}{ Expected return } & \multicolumn{2}{|c|}{ Actual return } & \multicolumn{2}{|c|}{ Expected return } & \multicolumn{2}{|c|}{ Actual return } \\
\hline & Points & Proportion & Points & Proportion & Points & Proportion & Points & Proportion \\
\hline 2 Points & 2.07 & 1.03 & 2.03 & 1.02 & 1.97 & 0.98 & 1.93 & 0.97 \\
\hline 4 Points & 4.07 & 1.02 & 4.10 & 1.03 & 3.93 & 0.98 & 4.10 & 1.03 \\
\hline 6 Points & 6.17 & 1.03 & 6.43 & 1.07 & 6.37 & 1.06 & 6.47 & 1.08 \\
\hline 8 Points & 8.77 & 1.10 & 8.63 & 1.08 & 8.60 & 1.08 & 8.67 & 1.08 \\
\hline Mean & - & 1.04 & - & 1.05 & - & 1.03 & - & 1.04 \\
\hline
\end{tabular}

0.73, $p=0.47$ for the risk game) or under tournament incentives (MW: $z=-1.094$, $p=0.28$ for the trust game; MW: $z=0.51, p=0.614$ for the risk game). Moreover, presentation order did not affect the mean proportion that trustees sent back (across four positive investments) in either the standard- (MW: $z=0.85, p=0.39$ ) or the tournament condition (MW: $z=0.75, p=0.45$ ).

\subsubsection{Expected and actual returns}

Table 7 shows the returns that trustors expected to receive as well as the actual number of points returned by trustees for each of the four possible positive investments. On average, trustors expected to do slightly better than breaking even on their investments.

For each possible positive investment trustors' expectation were on average close to the actual returns. Aggregated over all four positive investments, the mean proportion which trustors expected back $(E[R]=E[Y] / 2 \times X)$ does not differ significantly from the mean actual proportion returned by trustees $(R=Y / 2 \times X)$ (WS: $z=0.06, p=0.95$ for standard incentives; and $z=0.14, p=0.89$ for tournament incentives). Moreover, the mean proportion trustees sent back (aggregated over all four positive investments) was similar in the standard and the tournament conditions (WS: $z=0.02, p=0.98$ ). The same also holds for the mean proportion trustors expected back (WS: $z=-0.21, p=0.83$ ).

\subsubsection{Investment decisions}

Figure 2 summarizes the main results for investment decisions in the trust and the risk games.

A 2 (incentives) $\times 2$ (game type) $\times 2$ (presentation order) mixed ANOVA of trustors' investment decisions revealed a significant main effect of incentives $(F[54,1]=20.4, p<0.0014)$, replicating thus the results of Experiment 1. Main effects of game type $(F[1,54]=1.66, p=0.20)$ and presentation order $(F[54,1]=$ $0.03, p=0.86$ ) were not significant. Most importantly, we find a significant interaction effect between game type and incentives. This interaction indicates that decision makers did not react to tournament incentives in the same way in the risk and the trust game $(F[54,1]=5.27, p=0.03)$. None of the other interactions was significant $(F s[1,54]<0.88, p>0.35)$. 


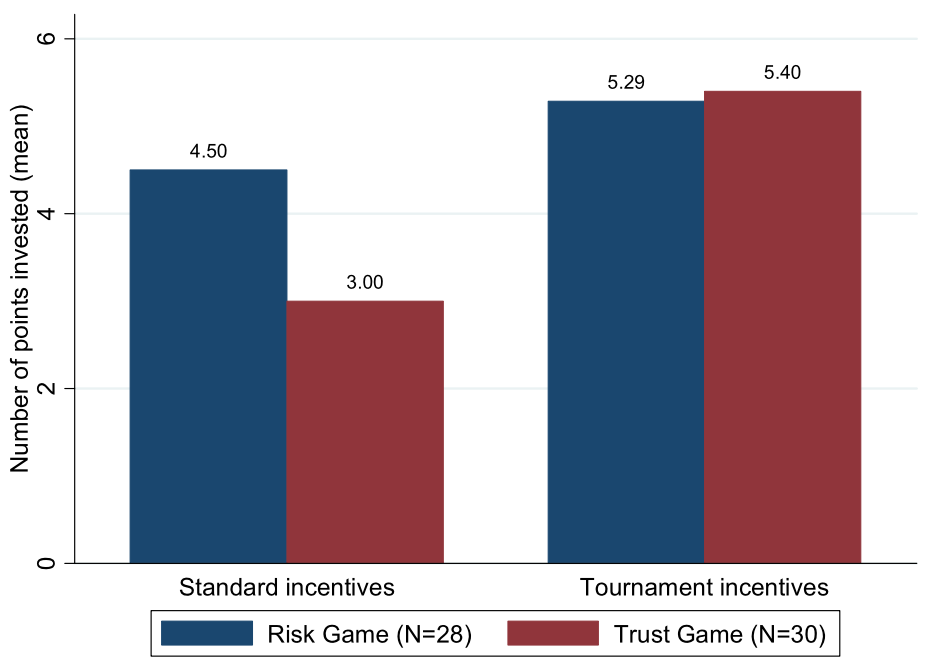

Fig. 2 Trustor decisions

An alternative way to determine the effect of tournament incentives is to analyze the difference between investment decisions made by each trustor under standard and tournament incentives. This difference provides a direct measure of the effect of the incentive schemes in the trust and risk games. In both games, tournament incentives had a positive effect on investment (WS: $z=-3.54, p<0.01$ for the trust game; and WS: $z=-1.63, p=0.10$ for the risk game). A direct comparison of this measure across the two games shows that the effect of tournament incentives was significantly larger in the trust than in the risk condition $(M=1.20, S D=1.45$ vs. $M=0.39$, $S D=1.20$; MW: $z=-2.04, p=0.04)$. In line with the ANOVA results, this finding indicates that although the increase in risk taking might explain a part of the overall effect of tournament incentives on trust, there is an additional effect that goes over and beyond what would be expected from the effect of tournament incentives on risk taking.

A comparison of the trust and the risk game under each of the two incentive schemes provides additional insights. Under standard incentives trustors invested significantly fewer points in the trust than in the risk condition (MW: $z=2.66$; $p<0.01$ ). This result is consistent with previous findings that have shown that individuals are less willing to trust when returns are determined by a human being than when they are determined by a lottery (Aimone and Houser 2010; Bohnet and Zeckhauser 2004; Hong and Bohnet 2007; cf., Kosfeld et al. 2005). By contrast, under tournament incentives trustors invested approximately the same amounts in the trust game as in the risk game (MW: $z=-0.35 ; p=0.73$ ). The latter results suggest that competitive pressures make typical non-financial concerns of trust relationships such as betrayal aversion and inequality aversion less salient. 


\subsection{Discussion}

Consistent with the results of Experiment 1, Experiment 2 showed that tournament incentives significantly increase the amount trustors are willing to invest in the trust game. Our results suggest that the effect is robust across different experimental setups. Importantly, the results of Experiment 2 also provide insights on the mechanism behind the increase of trust under tournament incentives.

The willingness to accept vulnerability in the trust game by investing a positive amount can generally be decomposed into three factors (Hong and Bohnet 2007). The first is the concern about being financially worse off than if one had not invested anything. Willingness to accept this kind of vulnerability is closely related to individual risk attitudes. In our setting, it is also likely to be influenced by strategic considerations about maximizing the chance of winning the tournament prize. Second, by showing trust, trustors make themselves vulnerable to disadvantageous inequality by accepting a possibility of being financially worse off than the trustee. Finally, trustors might be concerned about being betrayed by trustees. This concern refers to negative feelings that trustors might experience when trustees do not reciprocate trust shown to them.

In the trust game condition, all three vulnerabilities are present. Trust might not pay off and thus leave trustors financially worse off. Showing trust might also lead to a situation in which trustees are considerably better off than trustors (since both trustors and trustees are endowed with the same number of points at the beginning of the game). Finally, trustees have the possibility to betray trust shown to them. On the other side, in the risk game condition where no second human player is involved only the first concern, i.e., risk considerations, should influence the choice of trustors.

Our results show that under standard incentives, investments in the trust game are considerably lower than in the risk game with the same random payoff distribution. This indicates that under standard incentives concerns about either outcome inequality or betrayal have a significant effect on trustors' decisions. Under tournament incentives, the difference between decisions in the trust and the risk game disappears which indicates that trustors no longer treat the investment decision in the risk and the trust game differently. These results suggest that in trust relationships, tournament incentives reduce the salience of non-financial considerations such as betrayal and inequality aversion.

In summary, our analysis of trustor decisions shows that tournament incentives increase trust via two mechanisms. First, trust increases as a result of a greater willingness to take risk - as suggested by higher investments under tournament than standard incentives in the risk game. Second, tournament incentives seem to eliminate trustgame specific considerations such as concerns about disadvantageous inequality or betrayal — as indicated by the equal investments under tournament incentives in the risk and the trust games.

Other results of Experiment 2 are in line with the findings from Experiment 1. In particular, trustors expected to approximately break even on their investments. As long as trustees were paid according to standard incentives, their expectations matched well the actual returns they received. Similar to Experiment 1, trustees did not seem to be influenced by the incentive schemes of their counterparts. In Exper- 
iment 2 this effect is even more considerable as trustees made their decisions in a within-subject design that allowed them to directly compare the two situations.

\section{General discussion}

This paper addresses the question how competitive reward structures in organizations affect trust and trustworthiness in relationships with third parties uninvolved in the competition. Previous studies focused on direct competition between partners and documented a negative effect of such competition on trust relationships (e.g., Ferrin and Dirks 2003; Harbring 2010; Tjosvold 1982, 1985). In contrast to the previous studies, our results show that competition among trustors increases the level of trust they show to third parties. We also find that the increase in trust is not driven by more positive expectations concerning the third party's trustworthiness but by a combination of increased risk-taking and lower sensitivity to trust-game specific non-financial considerations. Our results suggest that under tournament incentives trustors' attention shifts away from concerns about the behavior of trustees, for example, a possible trust betrayal, towards beating their competitors for the tournament prize.

The competitive "blindness" to otherwise typical trust considerations is consistent with previous literature that has shown that competition can cause individuals to narrowly focus on their "desire to win" and ignore other relevant considerations $(\mathrm{Ku}$ et al. 2005; Malhotra 2010). Further studies that will explore the effect of tournament incentives on economic behavior should consider the effect of competitive blindness of human behavior in order to have a compete picture.

We find that while tournament incentives have a positive effect on trust, they strongly decrease trustworthiness. There are two possible reasons for this. First, from the trustee's point of view, tournament incentives increase the "price" of trustworthiness in terms of foregone expected payoff. Andreoni and Miller (2002) found that when the price of altruism was high in terms of forgone payoff relative to the increase in the recipient's payoff, participants in a dictator game showed considerably less other-regarding behavior. In our experiments, under standard incentives, trustees who send back a large proportion of the amount received still obtain a positive payoff of either 4 or $5 €$ (endowment), in addition to the amount kept. By contrast, under tournament incentives being trustworthy can reduce the final payoff from either 8 or $12 €$ to $0 €$. Second, in addition to these "economic" considerations, several psychological factors can lower trustworthiness. For example, participants may experience an anticipated regret of not winning the tournament prize. Alternatively, competitive pressure may give a "moral excuse" not to reciprocate trust. Our results suggest that competition may significantly reduce the sensitivity of trustees to such considerations as inequality aversion and preferences for reciprocity. Similar to the effect on trustors, competition seem to reduce the focus of attention of trustees thereby "blinding" them with respect to non-monetary considerations typically present in trust relationships.

Another striking finding is that both trustors and trustees were myopic to the incentives of their partners. Importantly, when participants were instructed about the procedure of the game and final payoffs, we took particular care to make sure they were aware of and fully understood the payoff structures of both trustors and trustees. 
Only then did participants get to know their own role in the game. And yet, our results show that while participants in both roles react to their own incentives structures, they fail to take into account the consequences of their partner's incentives. Most importantly, trustors do not trust less when trustees are paid according to tournament incentives (Experiment 1). This happens because trustors do not anticipate the lower levels of trustworthiness under these circumstances and thus substantially overestimate expected returns. This is even more surprising considering that trustors' expectations were unbiased when trustees were paid according to standard incentives.

Similarly, we find that whether participants judge the decisions of their partners as fair is only driven by the amount they receive. Neither trustors nor trustees seem to take into account different motives and constraints their partners have under tournament incentives. Consistent with this reasoning is the fact that in both experiments trustees do not honor trust less when it is caused by competitive pressures rather than altruistic preferences or positive expectations. Tor and Bazerman (2003) reported a related result in the context of dyadic and multi-party negotiations. Similar to our study, they found that during negotiations individuals focused solely on their own incentives and failed to consider the decisions of their negotiation partners, the specific rules of the negotiation, and the interaction between the two. As a consequence, participants made suboptimal decisions and achieved inefficient outcomes in the negotiation.

Opposite to these findings, McCabe et al. (2003) reported that in their study, differences in trustees' perceptions of the intentions of their counterparties had a strong effect on their own reciprocal decisions. We argue that the salience of intentionality in the McCabe et al.'s study could be one reason of these results. They compared two situations in which trustors could either clearly signal trust by forgoing an outside option or did not have the possibility to do so. As a consequence, the intentions of trustors were totally transparent for trustees. In contrast, in our study, the salience of intentions across conditions was less evident. Our results suggest that the perceptions of intentions of counterparties are often inaccurate and people are not sufficiently sensitive to the situational constraints their counterparties face (see also Gilbert and Malone 1995).

Overall, our results indicate that competition can increase trust in the short run. However, what would be the effect in long lasting work relationships where partners are likely to be both in the role of trustors and trustees at different points in time? A business consultant who works under intense competitive pressure will show high levels of trust to her clients. At the same time she might not reciprocate trust shown to her. In repeated interactions with changing trustor-trustee roles, such behavior might result in an inefficient work relationship characterized by suspicion and ill feelings. On the other side, if - as our results indicate-competitive pressure causes individuals to become less sensitive to non-financial considerations, they might also react less negatively when trust is not fully reciprocated and continue to trust as long as they expect to obtain at least a small financial benefit from it. Future research should explicitly explore the effect of tournament incentives on trust in repeated interactions. In repeated interactions, several additional factors such as learning and reputation building will also play a role. In standard trust games where interactions are repeated with the same partner, average levels of trust and trustworthiness have been shown to be 
considerably higher than in one-shot games (Cochard et al. 2004). In environments structured as tournaments, the need to build reputation is likely to counteract with the competitive pressure. Thus, trust and trustworthiness would be determined by the relative salience of the two forces. In such contexts, it would also be illuminating to study the behavior of trustors who face untrustworthy trustees. Would trustors still be immune to possible inequalities and trust betrayal and continue to trust as long as it is in their own long-term financial interest? We leave this intriguing question for future research.

In addition to exploring the consequences of tournament incentives in trust relationships, it would also be illuminating to explore their effect in other settings. For example, addressing the effect of tournament incentives in the context of coordination games, common-pool resource dilemmas or ultimatum games might provide interesting insights with respect to unintended consequences on third-party relationships.

Our findings also have implications for managerial practice. As we have shown, introducing a competitive incentive scheme within an organization can have important consequences for relationships not only between direct competitors but also for relationships with third parties. While managers are likely to be aware of changes in the relational dynamics between individuals who directly compete with each other, the indirect effect on third-party relationships is likely to be regularly unacknowledged. Relationships of individuals with third parties like clients, subordinates or members of other divisions are of fundamental importance for the effective functioning of organizations. In fact, interactions of this kind occur in practice probably just as frequently as interactions between peers directly competing with each other. Our results call for caution when introducing or abolishing competitive incentives schemes since such schemes can have an unexpected effect (positive or negative) on the relationships with third parties.

We are aware that trust relationships between employees within organizations are much richer than in laboratory experiments. As a consequence, our study is only one step toward a better understanding of the relation between competition-based incentives and trust relationships. Given the widespread use of competitive reward structures in organizations, further research in this direction can make important contributions not only to the theoretical literature on incentives but also to managerial practice.

Acknowledgements The authors appreciate the insightful comments by Max Bazerman, Iris Bohnet, Uri Gneezy, Eric Johnson, Marc Willinger, and two anonymous reviewers. The paper has benefited from presentations at the Economic Science Association European Meeting at the University of Innsbruck, Austria, and SJDM Meeting in Boston. This research was financed partially by a grant from the INSEAD Alumni Fund.

\section{References}

Andreoni, J., \& Miller, J. (2002). Giving according to GARP: An experimental test of the consistency of preferences for altruism. Econometrica, 70(2), 737-753.

Aimone, J. A., \& Houser, D. (2010). What you don't know won't hurt you: A laboratory analysis of betrayal aversion (Working paper). George Mason University. 
Aquino, K., \& Reed, A. (2002). The self-importance of moral identity. Journal of Personality and Social Psychology, 83, 1423-1440.

Ashraf, N., Bohnet, I., \& Piankov, N. (2006). Decomposing trust and trustworthiness. Experimental Economics, 9(3), 193-208.

Bachmann, R., \& Zaheer, A. (2006). Handbook of trust research. Cheltenham: Edward Elgar.

Bellemare, C., \& Kröger, S. (2007). On representative social capital. European Economic Review, 51, 183-202.

Berg, J., Dickhaut, J., \& McCabe, K. (1995). Trust, reciprocity, and social history. Games and Economic Behavior, 10, 122-142.

Bohnet, I., \& Zeckhauser, R. (2004). Trust, risk and betrayal. Journal of Economic Behavior \& Organization, 55, 467-485.

Boyle, M. (2001). Performance reviews: Perilous curves ahead. Fortune 15 May.

Brown, K. C., Harlow, W. V., \& Starks, L. T. (1996). Of tournaments and temptations: An analysis of managerial incentives in the mutual fund industry. The Journal of Finance, 51, 85-110.

Camerer, C. F. (2003). Behavioral game theory. Princeton: Princeton University Press.

Chaudhuri, A., \& Gangadharan, L. (2007). An experimental analysis of trust and trustworthiness. Southern Economic Journal, 73, 959-985.

Csukas, C., Fracalanza, P., Kovacs, T., \& Willinger, M. (2008). The determinants of trusting and reciprocal behaviour: Evidence from an intercultural experiment. Journal of Economic Development, 33, 7195.

Cochard, F., Van, P. N., \& Willinger, M. (2004). Trusting behavior in a repeated investment game. Journal of Economic Behavior \& Organization, 55, 31-44.

Dirks, K. T., \& Ferrin, D. L. (2001). The role of trust in organizational settings. Organization Science, 12, 450-467.

Eckel, C. C., \& Wilson, R. K. (2004). Is trust a risky decision? Journal of Economic Behavior \& Organization, 55(4), 447-465.

Ferrin, D. L., \& Dirks, K. T. (2003). The use of rewards to increase and decrease trust: Mediating processes and differential effects. Organization Science, 14(1), 18-32.

Fukuyama, F. (1995). Trust: The social virtues and the creation of prosperity. New York: Free Press.

Gaba, A., \& Kalra, A. (1999). Risk behavior in response to quotas and contests. Marketing Science, 18, $417-434$.

Gambetta, D. (1988). Trust: Making and breaking cooperative relations. New York: Basil Blackwell.

Gilbert, D. T., \& Malone, P. S. (1995). The correspondence bias. Psychological Bulletin, 117(1), 21-38.

Glaeser, E. L., Laibson, D., Scheinkman, J., \& Soutter, C. (2000). Measuring trust. The Quarterly Journal of Economics, 115(3), 811-846.

Greenwald, A. G. (1980). The totalitarian ego: Fabrication and revision of personal history. The American Psychologist, 35, 603-618.

Harbring, C. (2010). On the effect of incentive schemes on trust and trustworthiness. Journal of Institutional and Theoretical Economics, 166(4), 690-714.

Harbring, C., \& Irlenbusch, B. (2008). How many winners are good to have? On tournaments with sabotage. Journal of Economic Behavior \& Organization, 65, 682-702.

Hong, K., \& Bohnet, I. (2007). Status and distrust: The relevance of inequality and betrayal aversion. Journal of Economic Psychology, 28, 197-213.

Houser, D., Schunk, D., \& Winter, J. (2010). Distinguishing trust from risk: An anatomy of the investment game. Journal of Economic Behavior and Organization, 74, 72-81.

Hvide, H. K. (2002). Tournament rewards and risk taking. Journal of Labor Economics, 20, 877-898.

Innocenti, A., \& Pazienza, M. G. (2006). Altruism and gender in the trust game (Working Paper). University of Siena.

Irlenbusch, B., \& Ruchala, G. (2008). Relative rewards within team-based compensation. Labour Economics, 15(2), 141-167.

Kosfeld, M., Heinrichs, M. Zak, P. J., Fischbacher, U., \& Fehr, E. (2005). Oxytocin increases trust in humans. Nature, 435, 673-676.

Kramer, R. M., \& Tyler, T. R. (1996). Trust in organizations: Frontiers of theory and research. Thousand Oaks: Sage.

Ku, G., Malhotra, D., \& Murnighan, J. K. (2005). Towards a competitive arousal model of decisionmaking: A study of auction fever in live and internet auctions. Organizational Behavior and Human Decision Processes, 96(2), 89-103.

Kumra, S., \& Vinnicombe, S. (2008). A study of the promotion to partner process in a professional services firm: How women are disadvantaged. British Journal of Management, 19(1), 65-74. 
Lazear, E. P. (1989). Pay equality and industrial politics. Journal of Political Economy, 97, 561-580.

Lazear, E. P., \& Rosen, S. (1981). Rank-order tournaments as optimum labor contracts. Journal of Political Economics, 89(5), 843-864.

Malhotra, D. (2010). The desire to win: The effects of competitive arousal on motivation and behavior. Organizational Behavior and Human Decision Processes, 111, 139-146.

McCabe, K., Rigdon, M., \& Smith, V. (2003). Positive reciprocity and intentions in trust games. Journal of Economic Behavior \& Organization, 52(2), 267-275.

Monin, B., \& Jordan, A. H. (2009). Dynamic moral identity: A social psychological perspective. In D. Narvaez \& D. Lapsley (Eds.), Personality, identity, and character: explorations in moral psychology (pp. 341-354). Cambridge: Cambridge University Press.

Murphy, K. (1998). Executive compensation. In O. Ashenfelter \& D. Card (Eds.), Handbook of labor economics (Vol. 3). Amsterdam: North Holland.

Rosen, S. (1986). Prizes and incentives in elimination tournaments. American Economic Review, 76, 701715.

Schotter, A., \& Sopher, B. (2006). Trust and trustworthiness in games: An experimental study of intergenerational advice. Experimental Economics, 9, 123-145.

Schwieren, C., \& Weichselbaumer, D. (2010). Does competition enhance performance or cheating? A laboratory experiment. Journal of Economic Psychology, 31(3), 241-253.

Tjosvold, D. (1982). Effects of cooperative and competitive interdependence and task complexity on subordinates' productivity, perception of leader, and group development. Canadian Journal of Behavioral Sciences, 14(1), 24-34.

Tjosvold, D. (1985). Dynamics within participation: An experimental investigation. Group and Organisational Studies, 10(3), 260-277.

Tor, A., \& Bazerman, M. H. (2003). Focusing failures in competitive environments: Explaining decision errors in the Monty Hall game, the Acquiring a Company game, and multiparty ultimatums. Journal of Behavioral Decision Making, 16, 353-374.

Willinger, M., Keser, C., Lohmann, C., \& Usunier, J. (2003). A comparison of trust and reciprocity between France and Germany: Experimental investigation based on the investment game. Journal of Economic Psychology, 24, 447-466. 